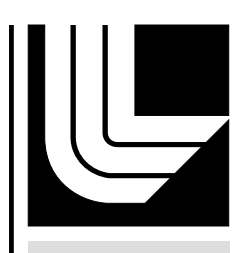

LA W REN CE LIVERMORE N A TIO NAL LABORATORY

Second Generation Toolset for Calculation of Induced Seismicity Risk Profiles

W. Foxall, J. Savy, S. Johnson, L. Hutchings, W.

Trainor-Guitton, M. Chen

April 11, 2013 
This document was prepared as an account of work sponsored by an agency of the United States government. Neither the United States government nor Lawrence Livermore National Security, LLC, nor any of their employees makes any warranty, expressed or implied, or assumes any legal liability or responsibility for the accuracy, completeness, or usefulness of any information, apparatus, product, or process disclosed, or represents that its use would not infringe privately owned rights. Reference herein to any specific commercial product, process, or service by trade name, trademark, manufacturer, or otherwise does not necessarily constitute or imply its endorsement, recommendation, or favoring by the United States government or Lawrence Livermore National Security, LLC. The views and opinions of authors expressed herein do not necessarily state or reflect those of the United States government or Lawrence Livermore National Security, LLC, and shall not be used for advertising or product endorsement purposes.

This work performed under the auspices of the U.S. Department of Energy by Lawrence Livermore National Laboratory under Contract DE-AC52-07NA27344. 


\section{nrap}

National Risk

Assessment Partnership

Second Generation Toolset for Calculation of Induced Seismicity Risk Profiles

2 April 2013

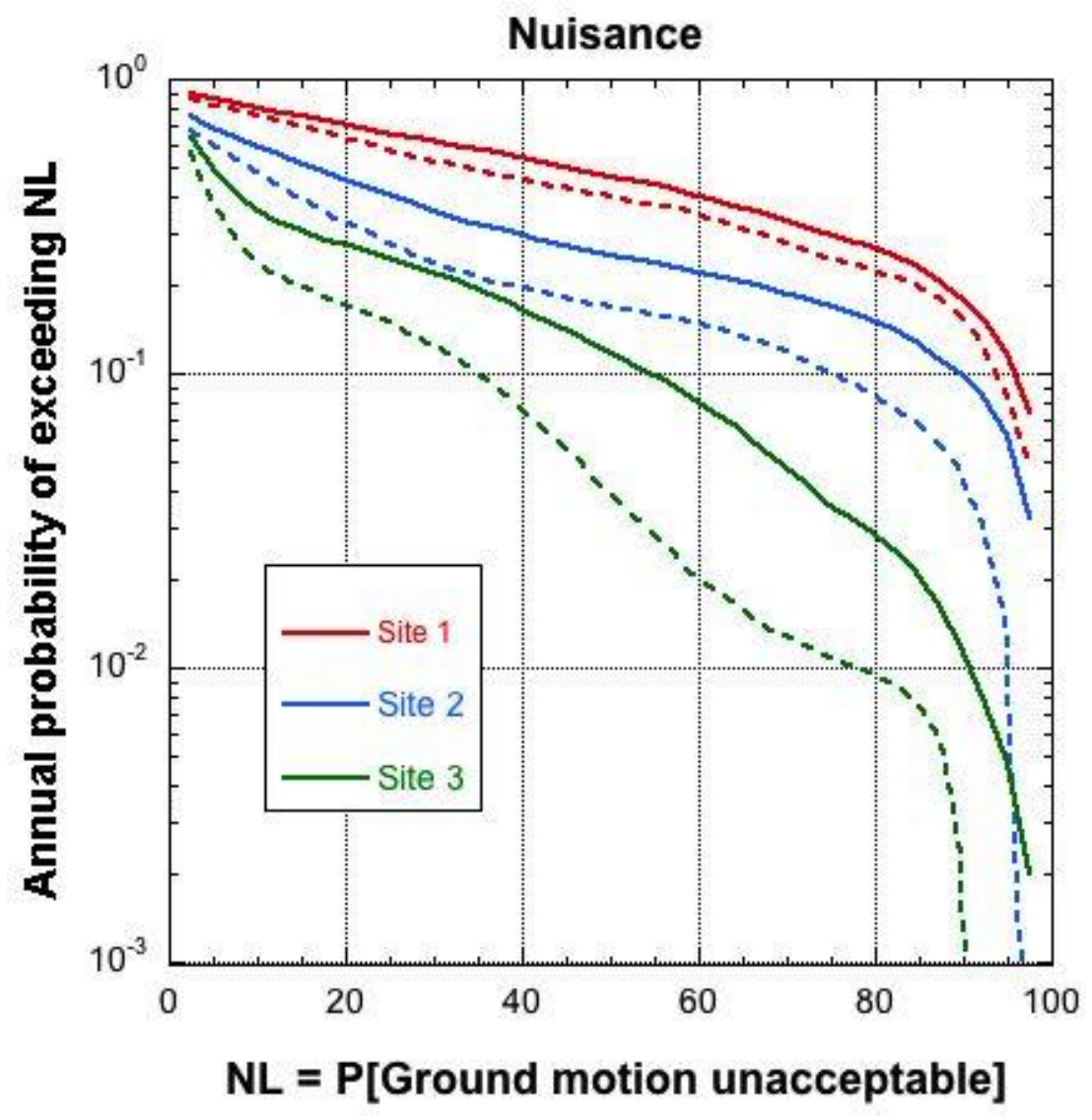

Office of Fossil Energy

NRAP-TRS-II-xxx-2013 


\section{Disclaimer}

This report was prepared as an account of work sponsored by an agency of the United States Government. Neither the United States Government nor any agency thereof, nor any of their employees, makes any warranty, express or implied, or assumes any legal liability or responsibility for the accuracy, completeness, or usefulness of any information, apparatus, product, or process disclosed, or represents that its use would not infringe privately owned rights. Reference therein to any specific commercial product, process, or service by trade name, trademark, manufacturer, or otherwise does not necessarily constitute or imply its endorsement, recommendation, or favoring by the United States Government or any agency thereof. The views and opinions of authors expressed therein do not necessarily state or reflect those of the United States Government or any agency thereof.

Cover Illustration: Risk of nuisance from ground shaking at three sites at different distances from two seismogenic faults. Nuisance for pre-injection (200 years) and injection (50 years) periods are shown as the dashed and solid curves, respectively.

Suggested Citation: Foxall, W., Savy, J., Johnson, S., Hutchings, L., Trainor-Guitton, W., and Chen, M. Second Generation Toolset for Calculation of Induced Seismicity Risk Profiles; NRAP-TRS-II-***-2013; NRAP Technical Report Series; U.S. Department of Energy, National Energy Technology Laboratory: Morgantown, WV, 2013; **p.

This work has been reviewed and released by LLNL (LLNL-TR-Xxxxx-DRAFT)

This work was performed by LLNL under Contract DE-AC52-07NA27344

An electronic version of this report can be found at: www.netl.doe.gov/nrap. 


\title{
Second Generation Toolset for Calculation of Induced Seismicity Risk Profiles
}

\author{
William Foxall ${ }^{1}$ \\ Jean Savy ${ }^{1,3}$, Scott Johnson ${ }^{1}$, Lawrence Hutchings ${ }^{2}$, \\ Whitney Trainor-Guitton ${ }^{1}$, and Mingjie Chen ${ }^{1}$
}

\footnotetext{
${ }^{1}$ Atmospheric, Earth and Energy Division, Lawrence Livermore National Laboratory 7000 East Ave., Livermore, CA 94551

${ }^{2}$ Earth Sciences Division, Lawrence Berkeley National Laboratory 1 Cyclotron Road, Berkeley, CA 94720

${ }^{3}$ Savy Risk Consulting 733 Arimo Avenue, Oakland, CA 94610
}

NRAP-TRS-II-Xxx-2013

Level II Technical Report Series

2 April 2013 
This page intentionally left blank 


\section{DRAFT}

Second Generation Toolset for Calculation of Induced Seismicity Risk Profiles

\section{Table of Contents}




\section{DRAFT}

Second Generation Toolset for Calculation of Induced Seismicity Risk Profiles

\section{List of Figures}

\section{List of Tables}




\section{DRAFT}

Second Generation Toolset for Calculation of Induced Seismicity Risk Profiles

\section{Acronyms and Abbreviations}

\begin{tabular}{|l|l|}
\hline \multicolumn{1}{|c|}{ Term } & \\
\hline$\mu_{0}$ & Base coefficient of friction \\
\hline$\lambda$ & Elastic Lame parameter \\
\hline$\mu$ & Elastic shear modulus \\
\hline$\sigma$ & Fault normal stress, ground surface \\
\hline$\tau$ & Fault shear stress \\
\hline A & Rate-and-state friction direct effect parameter (e.g. Marone, 1998) \\
\hline $\mathrm{b}$ & Rate-and-state evolution parameter \\
\hline $\mathrm{d} \sigma / \mathrm{dz}$ & Normal stress gradient \\
\hline $\mathrm{D}_{\mathrm{c}}$ & Rate-and-state slip-weakening distance \\
\hline DOE & Department of Energy \\
\hline fA & RSQSim A correction factor \\
\hline $\mathrm{g}$ & Gravitational acceleration $=9.81$ m.s \\
\hline GCS & Geological carbon storage \\
\hline LBNL & Lawrence Berkeley National Laboratory \\
\hline LLNL & Lawrence Livermore National Laboratory \\
\hline $\mathrm{M}$ & Earthquake magnitude \\
\hline $\mathrm{M}_{\mathrm{w}}$ & Earthquake moment magnitude \\
\hline NRAP & National Risk Assessment Partnership \\
\hline PSHA & Probabilistic seismic hazard analysis \\
\hline PSRA & Probabilistic seismic risk assessment \\
\hline Q & Seismic intrinsic attenuation factor \\
\hline s & Stress overshoot factor \\
\hline USGS & U.S. Geological Survey \\
\hline V & Long-term fault slip rate \\
\hline$V_{\text {eq }}$ & Coseismic fault slip velocity \\
\hline $\mathrm{v}_{\mathrm{p}}$ & Crustal P-wave velocity \\
\hline $\mathrm{v}_{\mathrm{s}}$ & Crustal S-wave velocity \\
\hline &
\end{tabular}




\section{DRAFT}

Second Generation Toolset for Calculation of Induced Seismicity Risk Profiles

\section{Acknowledgments}

This work was completed as part of National Risk Assessment Partnership (NRAP) project. Support for this project came from the Department of Energy (DOE) Office of Fossil Energy's Crosscutting Research program. The authors wish to acknowledge Robert Romanosky (NETL Strategic Center for Coal) and Regis Conrad (DOE Office of Fossil Energy) for programmatic guidance, direction, and support.

The authors also wish to acknowledge Prof. Jim Dieterich and Dr. Keith Richards-Dinger at the University of California, Riverside for making the RSQSim earthquake simulation program available to us and for their continued interest and support. 


\section{DRAFT}

Second Generation Toolset for Calculation of Induced Seismicity Risk Profiles

\section{ABSTRACT}

This report describes development and demonstration of Generation 2 of the NRAP toolset for probabilistic analysis of risks from earthquakes that could potentially be induced by $\mathrm{CO}_{2}$ injection. The capability to carry out hazard estimation at multiple sites and over multiple time periods of interested has been added to the integrated toolset. The capability to carry out hazard runs that utilize multiple simulations, based on random sampling of input parameter distributions, to bound hazard curve uncertainties has also been added. During Generation 2, an innovative method of constructing "nuisance fragility" functions for seismic ground motion has been developed. These functions are combined with seismic hazard curves to estimate of the risk of nuisance from ground shaking. The results described in this report demonstrate the functionality of the toolset based on its application to hypothetical scenarios involving one or two faults. Additional computer program development, including code parallelization, will be needed to bring the toolset up to full functionality. Alternative approaches to implementing the simulation-based approach to probabilistic induced seismicity hazard analysis are also outlined. 


\section{DRAFT}

Second Generation Toolset for Calculation of Induced Seismicity Risk Profiles

\section{INTRODUCTION}

Injecting $\mathrm{CO}_{2}$ into the shallow layers of the Earth's crust for geological carbon sequestration GCS) has, in common with the injection of other fluids, the potential for inducing seismic events under certain circumstances. In general, the vast majority of these events are far too small to be perceptible, but under some conditions they have been felt at the ground surface, and in extremely rare cases have caused structural damage. Like for other potential risks, the objective of a $\mathrm{CO}_{2}$ operation is avoid the occurrence of felt events through proper planning and engineering design based on rigorous risk analysis, before and during injection and as part of long-term stewardship. Therefore, the National Risk Assessment Partnership (NRAP) is developing a toolset for assessment of risk associated with induced seismicity that could potentially occur as a result of $\mathrm{CO}_{2}$ injection.

The general nature of the risk assessment problem for induced seismicity is described in a previous NRAP technical report (Foxall et al., 2012). That report also describes NRAP's overall approach to the problem and Generation 1 development of the probabilistic seismic hazard analysis (PSHA) method, which is the first component of the complete probabilistic seismic risk assessment (PSRA). NRAP has adopted the well-established conventional approach to PSRA for damage from naturally-occurring tectonic earthquakes, but modified it to deal with the timeand space-dependent characteristics of induced seismicity and to extend the risk assessment to include nuisance caused by small events that may be felt in nearby communities. NRAP's PSRA method is being developed for risk assessment beginning at the planning and design stages of a GCS project, when no record of induced seismicity exists. Therefore, development of the NRAP toolset is presently focused on physics-based simulation to generate catalogs of induced earthquakes from which occurrence frequency-magnitude statistics can be estimated. The toolset also employs a physics-based analytical method to calculate ground shaking from the simulated earthquakes.

The Generation 1 effort was devoted primarily to constructing the computational framework for the PSHA component of the toolset by integrating three program modules, as described in Foxall et al. (2012). The functionality of the PSHA component was then demonstrated by applying it to a hypothetical $\mathrm{CO}_{2}$ injection scenario that incorporated a single fault. For that demonstration, the hazard was calculated for a single time period and was limited to one epistemic realization of the fault, tectonic loading and crustal parameters. As explained in the Generation 1 report, epistemic uncertainties stem from a lack of knowledge of the true parameter values, whereas aleatory uncertainties express the natural stochastic variability of a physical property, such as the heterogeneous distribution of strength on a fault plane. Multiple realizations are required to sample the full distributions of both epistemic and aleatory uncertainties in the input parameters and to propagate them through the calculation to determine the uncertainty bounds on the hazard.

The objective of the Generation 2 development described in this report was to expand the capabilities of the toolset to include:

- multiple faults

- multiple epistemic realizations of fault geometry, frictional parameters and tectonic shear loading rate

- multiple aleatory realizations of fault properties within each epistemic realization 


\section{DRAFT}

Second Generation Toolset for Calculation of Induced Seismicity Risk Profiles

- calculation of nuisance risk from the hazard using "nuisance fragility" curves developed as part of the project

- calculation of hazard and risk over several time periods of varying length and at sites at different distances from the injection well

The Generation 1 hypothetical GCS injection scenario described in Foxall at al. (2012) was extended to include multiple faults having different strikes and dips. The regional tectonic shear loading rate could be varied, and the long-term slip rate resolved on each fault was consistent with its strike, dip and rake (slip vector). As in Generation 1, the fluid pressure distributions on the faults were given by a reservoir flow model driven by injection at a single well. The pressures developed along the faults during the Generation 2 simulations are similar to those in the Generation 1 scenario, but they increase to the peak pressure and then fall off at much slower rates. This produces a much longer period of elevated pressure on the faults, which results in higher rates of induced seismicity and hence larger statistical samples from which to derive hazard estimates.

Development of the nuisance fragility curves in Generation 2 was based on knowledge built up in the mining, construction and civil engineering communities of sensitivity to ground motions and vibrations caused by blasting, operation of heavy machinery, heavy vehicular traffic, etc. 


\section{DRAFT}

Second Generation Toolset for Calculation of Induced Seismicity Risk Profiles

\section{METHOD}

The overall structure of the PSRA toolset shown schematically in Figure 1 is similar to the Generation 1 PSHA toolset, except that the risk calculation has now been implemented in the SIMRISK module. The functioning of the hazard component is essentially the same as described in Foxall et al. (2012), except that implementation of the multiple fault, multiple realization and multiple time period capabilities have been completed to achieve full functionality. Further details on the implementation of earthquake simulations in the toolset are discussed below, together with an outline of the risk calculation methodology.

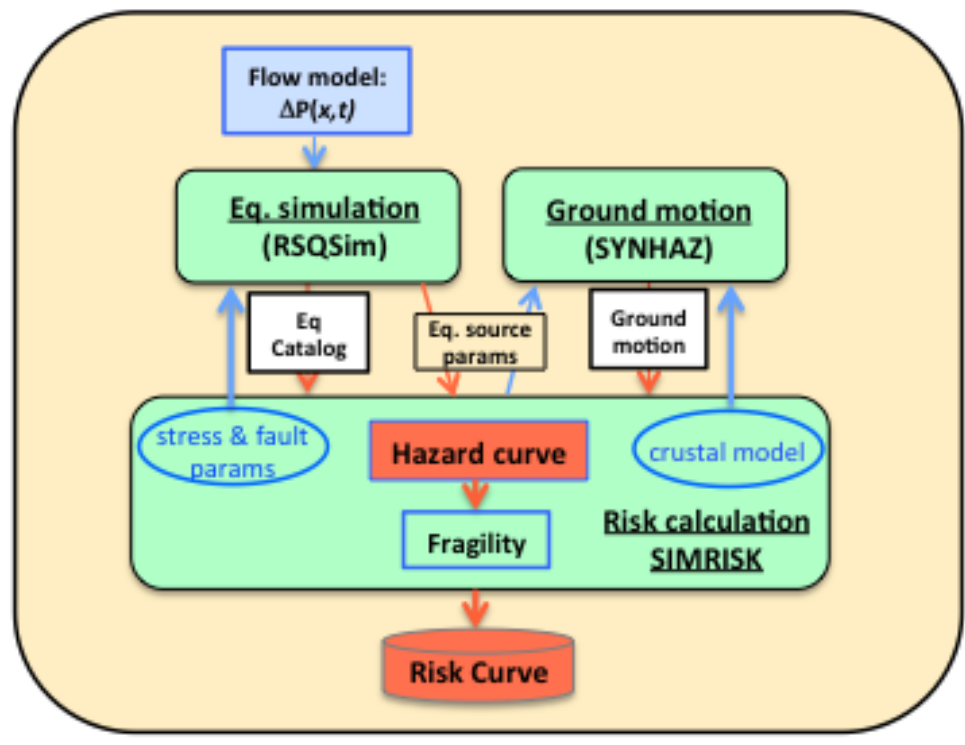

Figure 1: Schematic diagram of the probabilistic seismic risk computational framework.

\subsection{Earthquake Simulation}

As described in Foxall et al. (2012), the role of earthquake simulation program RSQSim (Richard-Dinger and Dieterich, 2012; Dieterich, 1995) in the toolset is to generate a seismicity catalog for each epistemic/aleatory realization passed by the risk calculation module SIMRISK. This is done by simulating seismicity sequences on the faults in the earthquake source model. The physics of the rate-and-state friction law that lies at the heart of RSQSim and its implementation in the program are described in a TRS report by Trainor-Guitton et al. (2013).

The fault geometries and long-term fault slip rates used in RSQSim simulations are sampled as epistemic parameters. Rate-and-state frictional parameters can be treated as either epistemic or aleatory (see Table 1). Appropriate ranges of key rate-and-state parameters were investigated by Trainor-Guitton et al. (2013). The pore pressure history on each fault element, input from an injection-driven flow calculation (described below), modifies the time-varying effective (confining) stress on that element, thus lowering its frictional strength until it fails in an earthquake. In essence, such induced events can be viewed as earthquakes that would have occurred eventually under the steady-state tectonic loading. The role of the evolving pore 


\section{DRAFT}

Second Generation Toolset for Calculation of Induced Seismicity Risk Profiles

pressure field is to accelerate the weakening of fault elements and hence increase their failure rates. Note, however, that the evolving pressure distribution coupled with the complex series of interactions on the fault resulting from coseismic stress transfers leads to significant changes in the frequency-magnitude statistics of the seismicity (see Trainor-Guitton et al. 2013), not merely an increase in the overall rate of activity at all magnitudes. Furthermore, the frequencymagnitude behavior under the influence of an evolving pressure field will change both in time and space.

In order to generate realistic earthquake frequency-magnitude statistics, heterogeneous distributions of constitutive properties on the fault planes are required (e.g. Ben-Zion, 2008). Such property distributions are randomly prescribed as aleatory initial conditions at the beginning of each simulation. The initial seismicity characteristics are strongly influenced by the prescribed distribution, but the complexity and randomness of the stress field on the fault resulting from seismic events evolves rapidly so that the initial conditions are rapidly forgotten. To ensure that this is the case, the events that occur within a specified initial burn-in period are discarded. The burn-in period is determined by initial standalone runs of RSQSim, and can be regarded as to the time it takes a fault to evolve to a mature state. Therefore, the implicit assumption is that the faults in the model are mature as opposed to newly formed.

\subsection{Hazard and Nuisance Risk Calculations}

After a catalog of earthquakes has been simulated by RSQSim, we calculate the seismic hazard $\mathrm{H}(\mathrm{x})$ corresponding to each catalog. Hazard curves generated in each epistemic simulation are processed to determine their statistical characteristics, and the results are weighted according to the weights assigned to the epistemic simulations. At this point in the project, all the epistemic parameters are randomly selected with uniform probability distribution, which results in an equal weight for all epistemic simulations. In order to show the time effect of the injection, the catalogs of earthquakes are sorted into several time periods. A separate hazard and nuisance is estimated for each period. Having calculated the hazard curves, the corresponding nuisance risk curves are calculated as described below.

The effects of earthquake ground-motion from medium to large earthquakes $\left(\mathrm{M}_{\mathrm{w}}>4.5\right)$ on structures is usually modeled with fragility functions that give the probability distribution of damage to a structure as a function of ground-motion intensity. Extensive literature is available in this domain, but it is limited to the physical effects of earthquakes, as exemplified by the FEMA catastrophe loss estimation project HAZUS (FEMA, 2013).

The effects of smaller ground-motion levels has been extensively studied for vibrations generated by mining and construction (Dowding, 1996), which has lead to development of deterministic acceptability criteria. It is well known that high pressure injections operations have caused complaints by local residents, e.g. at the Geysers geothermal field in California. Therefore, it is important to bound the limits of acceptability of these operations. A recent DOE publication (Majer, et al., 2012) suggested criteria for the acceptability of ground motions associated with enhanced geothermal systems (EGS) that in general can also be applied to seismicity potentially induced by GCS.

We define nuisance risk as the probability that an individual will not find the seismic environment acceptable. We use the FEMA general approach to model the response of 


\section{DRAFT}

Second Generation Toolset for Calculation of Induced Seismicity Risk Profiles

individuals to ground-motion, and we use the DOE criteria to anchor the human response "fragility functions".

Given the peak acceleration of the ground-motion $X$, the fragility function $g(X)$ gives the probability that level $X$ is not acceptable (event $\{U\}$ ), and it is modeled by a typical fragility curve (Figure 2):

$$
g(X)=P[U \mid X]=\Phi\left(\frac{\operatorname{Ln}\left(\frac{X}{A}\right)}{\beta}\right)
$$

Where: $\mathrm{U}$ is the event $\{$ Unacceptable

$\mathrm{X}$ is the ground motion acceleration level

$\mathrm{A}$ is the acceleration level at which there is a $50 \%$ probability that an individual would find the level $\mathrm{X}$ unacceptable (the anchor value)

$\beta$ is a measure of the aleatory uncertainty $\Phi$ is the cumulative Gaussian, and Ln is natural logarithm.

Alternatively, $\mathrm{g}(\mathrm{X})$ can be interpreted as the proportion of individuals who would find the ground-motion $\mathrm{X}$ to be unacceptable

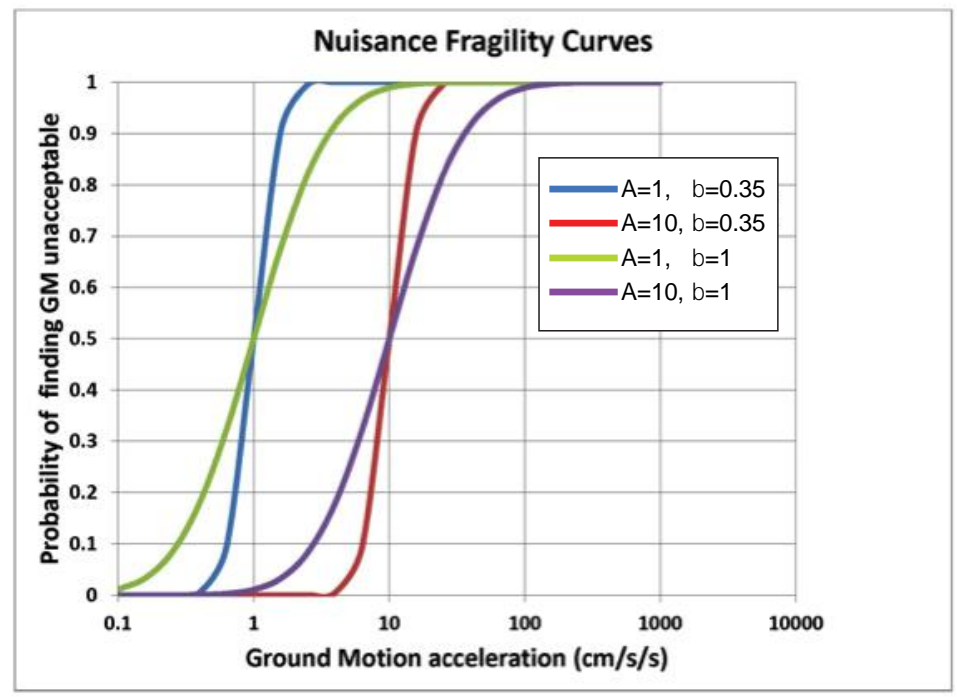

Figure 2: Nuisance fragility curves showing the probability that an individual would find a given ground acceleration unacceptable for different combinations of the anchor value of logmedian acceleration and its epistemic uncertainty, $\beta$.

Figure 2 shows two sets of fragility curves to express the epistemic uncertainty in the anchor values. One is anchored at a log-median value of $A=1 \mathrm{~cm} / \mathrm{s} / \mathrm{s}$ and the other at $10 \mathrm{~cm} / \mathrm{s} / \mathrm{s}$. The figure also shows variability in the $\beta$ parameter that reflects its epistemic uncertainty. These epistemic uncertainties are not accounted for at the present time in the SIMRISK, but they will be easy to implement in future development. 


\section{DRAFT}

Second Generation Toolset for Calculation of Induced Seismicity Risk Profiles

Let $\mathrm{z}$ be the level of nuisance. $\mathrm{z}$ is a number between 0 and 1 , as it expresses the probability of an event, and let $\mathrm{R}(\mathrm{z})$ be the probability of exceedance of level $\mathrm{z}$. Therefore, the probability of exceedance of $\mathrm{z}$ is equal to the probability of exceedance of the ground-motion value that produce $\mathrm{z}$. If $\mathrm{H}(\mathrm{X})$ is the seismic hazard, which represents the probability of exceedance of $\mathrm{X}$, then:

$R(z)=P[Z \geq z]=P[g(X) \geq z]=P\left[g^{-1}(\mathrm{z}) \geq X\right]=H\left(g^{-1}(\mathrm{z})\right) \quad$ Eq. 2

Where:

$\mathrm{R}(\mathrm{z})$ is the risk of nuisance, a probability between 0 and 1 ,

$\mathrm{g}^{-1}$ is the inverse function of $\mathrm{g}$, the fragility function,

$\mathrm{H}(\mathrm{x})$ is the seismic hazard function

Equation 2 combines the hazard curve for each time period with the fragility curve to estimate the risk of nuisance, $\mathrm{R}(\mathrm{z})$, as shown schematically in Figure 3.
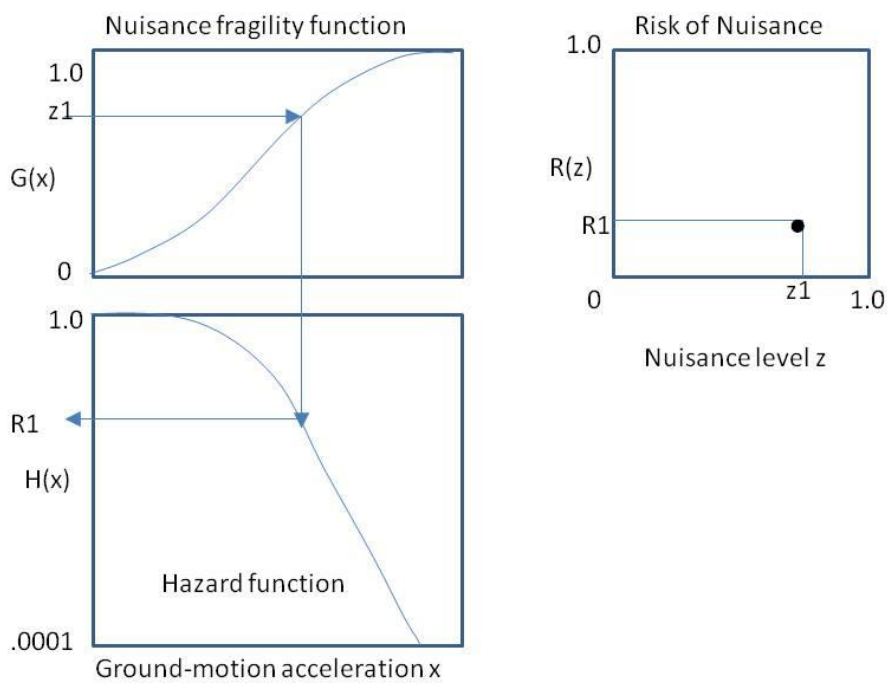

Nuisance level z

Figure 3: Schematic representation of estimation of risk of nuisance by combining a hazard and nuisance fragility curve.

Nuisance results presented in this report used $A=10 \mathrm{~cm} / \mathrm{s} / \mathrm{s}$ and $\beta=0.80$ (Majer, et.al, 2012). Future developments in this project will investigate other ground-motion parameters, such as velocity, or spectral representations to determine which is most appropriate to modeling of human response. 


\section{DRAFT}

Second Generation Toolset for Calculation of Induced Seismicity Risk Profiles

\section{RESULTS}

Simulation Scenario: The scenario used for Generation 2 was developed from the Generation 1 described in Foxall at al. (2012) by adding an additional fault. Figure 4 shows the locations of the two faults used as sources of induced earthquakes for the Generation 2 hazard and risk calculations. The faults are shown in relation to the injection well and two of the sites at which ground motions are calculated; a third site is located off the map approximately $5 \mathrm{~km}$ due west of the map center. The map shows the traces of the upper edges of Fault 1 and Fault 2 at a depth of $885 \mathrm{~m}$. Fault 1 extends vertically to a depth of $2400 \mathrm{~m}$. Fault 2 dips $60^{\circ} \mathrm{NW}$ to a depth of 3000 $\mathrm{m}$; the projection of the plane of Fault 2 on to the horizontal surface is shown dashed on Figure 4. Hazard and risk calculations presented here were carried out for seismicity simulated on Fault 1 alone or on both Faults 1 and 2. The subsection of Fault 2 shown as the dotted green rectangle on Figure 4 was used in the two-fault hazard/risk analyses. This subsection extends from $885 \mathrm{~m}$ depth down-dip to $2300 \mathrm{~m}$. The long-term regional tectonic loading is applied in a NW-SE direction so that right-lateral strike-slip motion occurs on Fault 1 and reverse dip-slip on Fault 2. The long-term slip rates on the faults are specified as epistemic parameters and are varied over the range 1 to $2 \mathrm{~mm} /$ year.

As discussed in Foxall et al. (2012), the scenario is representative of realistic field conditions in that it is based on a geological model derived from petrophysical and other properties measured at an actual GCS site. However, the scenario faults, fault properties and tectonic loading are hypothetical. The sole purpose of the scenario is to test and demonstrate the second generation hazard and risk toolset, rather than represent an actual field situation. The range of long-term fault slip rates applied as tectonic loading is representative of regions having moderate seismicity. This tectonic characterization was chosen to generate sufficient seismicity to yield valid statistical samples from which to calculate hazard and associated uncertainties over time periods ranging from tens to hundreds of years.

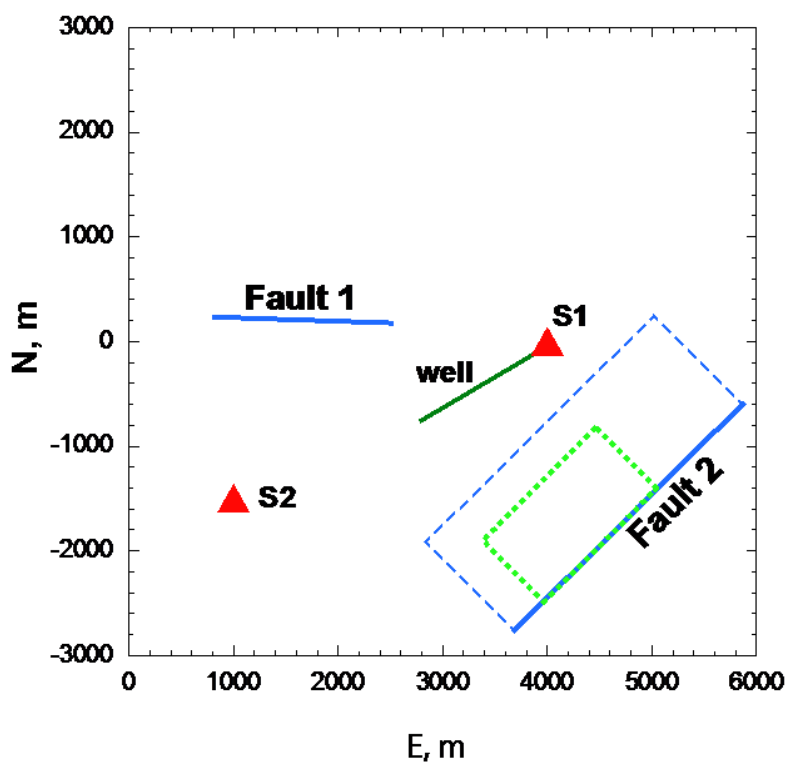




\section{DRAFT}

Second Generation Toolset for Calculation of Induced Seismicity Risk Profiles

Figure 4: Synthetic seismic risk calculation scenario showing faults, surface recording sites (red) and the horizontal section of the injection well (green). See text for explanation of faults.

Pore Pressure Model: A NUFT flow model simulates the injection of super-critical $\mathrm{CO}_{2}$ along the length of the horizontal well section into a $20 \mathrm{~m}$-thick reservoir at a depth of $1800 \mathrm{~m}$. The simulation was carried for a total time period of 200 years. The injection took place over the first 50 years at a rate of 0.6 million metric tons per year. The initial pore pressure was hydrostatic. Figures 5 shows 3D views of the pore pressure distribution after 50 years, when the pressure peaks in the reservoir. The pressure histories (offset by +200 years - see below) at the points of intersection of the reservoir with Faults 1 and 3 closest to the well are shown in Figure 6. The pressure histories on the fault planes are extracted and written to a file by inserting the faults into the time-dependent 3D time pressure distribution and interpolating on to a defined set of fault grid cells. These pressure histories are then used by interpolating from the pressure grid on each fault to the fault elements used in the earthquake simulations. As shown on Figure 6, the pressure trends at 200 years are extrapolated to fall back to hydrostatic at 425 years. The entire set of fault pressure histories can be offset in time to enable them to be applied at any stage of an earthquake simulation.

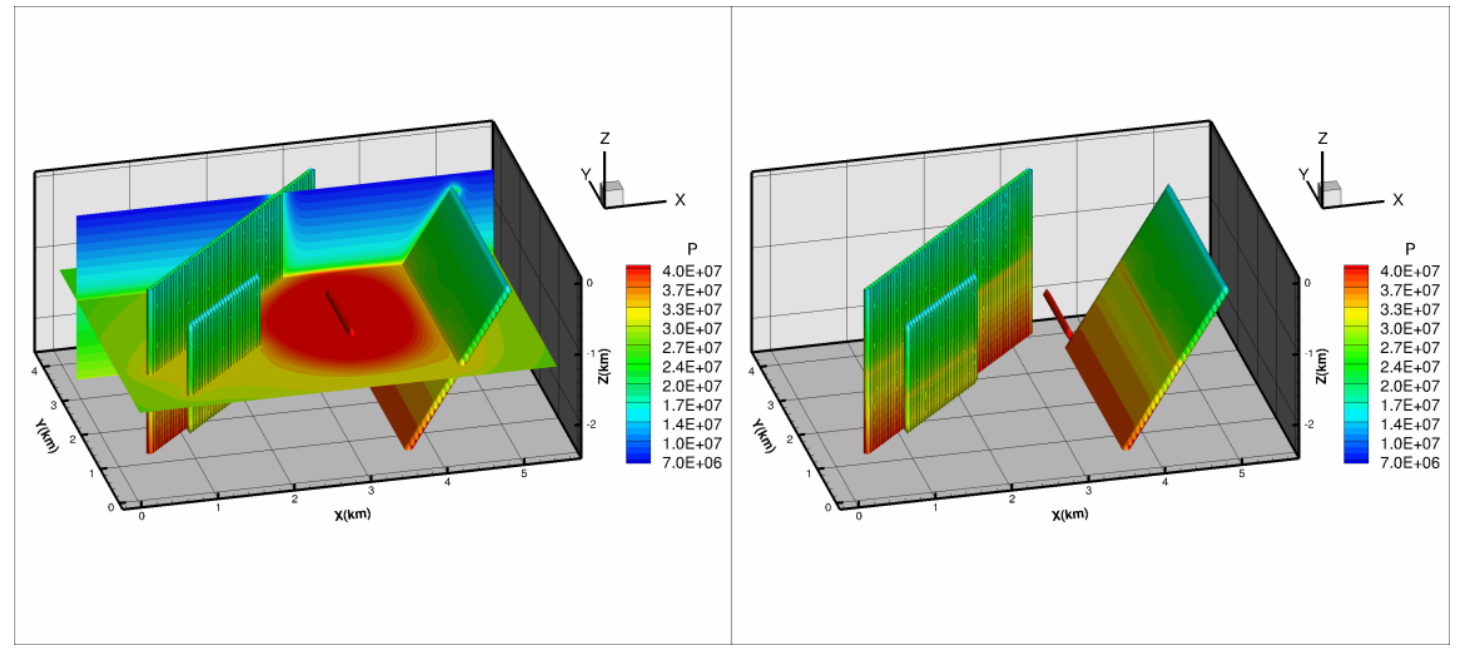

Figure 5: Pore pressure distribution within the horizontal reservoir at $1800 \mathrm{~m}$ depth and on three faults 50 years after the start of injection. The two faults used in the present scenario are the smallest vertical fault (Fault 1) and the 60 dipping fault (Fault 2).

Earthquake Simulations: The hazard and nuisance risk curves and their associated uncertainty bounds are calculated from a sequence of RSQSim simulations. Each hazard/risk calculation uses one realization of the epistemic parameters within which there are a specified number (usually 2 in the present work) samples of the aleatory parameters; i.e. the total number of catalog simulations per run is the number of epistemic realizations multiplied by the number of aleatory samples. The epistemic and aleatory parameter ranges are given in Table 1 together with the values of fixed parameters. The RSQSim simulations were run for 700 years after an initial burn-in period of 500 years. The burn-in time was determined based on standalone runs of RSQSim used to assess the time taken to stabilize the earthquake frequency-magnitude distribution under constant hydrostatic pore pressure. The fault pore pressure time histories generated from the NUFT simulation are applied 200 years after the end of the burn-in period. 


\section{DRAFT}

Second Generation Toolset for Calculation of Induced Seismicity Risk Profiles
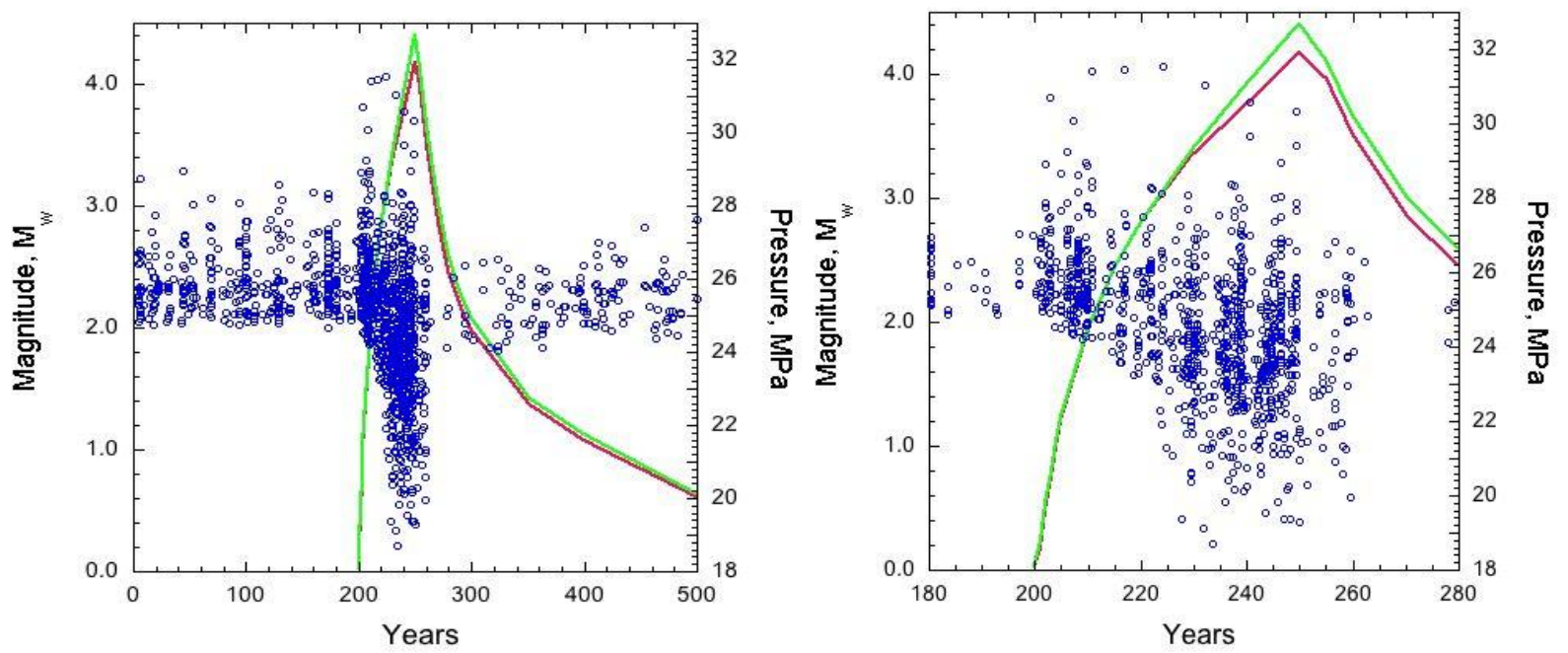

Figure 6: Example of a seismicity history simulated on two faults using RSQSim . Pressures shown are at reservoir depth $(1800 \mathrm{~m})$ at points on Faults 1 (red) and 2 (green) closest to the injection well.

Figure 6 (left) shows the first 500 years (post burn-in) of the seismicity time history generated by a standalone RSQSim two-fault simulation using parameters within the ranges used in the hazard calculations. The corresponding pressure histories at the fault/reservoir intersection points closest to the injection well are also shown. It can be seen that the induced seismicity response begins within the first year of the pressure pulse reaching the fault at pressures only a few MPa above hydrostatic $(18 \mathrm{MPa})$. There is then a rapid increase in the rate of seismicity above the pre-injection minimum magnitude $\left(\sim \mathrm{M}_{\mathrm{w}} 2\right)$, and the later onset of a prolonged burst of smaller events between $\mathrm{M}_{\mathrm{w}} 0$ and $\mathrm{M}_{\mathrm{w}} 2$. Larger events approaching the maximum magnitude $\left(\sim \mathrm{M}_{\mathrm{w}} 4\right)$ corresponding to the area of the largest fault, and about 1 magnitude unit above the seismicity during the pre-injection period, occur within the first 2 years. Figure 6 (right) shows a 100-year period centered on the burst of induced seismicity. The occurrence of events below $\mathrm{M}_{\mathrm{w}} 2$ begins about 15 years after the start of injection and continues until about 10 years after the peak in the pressure curve at 250 years. The enhanced rate of occurrence of larger magnitude events continues until peak pressure is reached and then abruptly falls to the pre-event level. Ten years after peak pressure the faults become entirely quiescent for about 20 years before activity gradually increases towards pre-injection levels.

Ground Motion Calculations: SYNHAZ ground motion calculations utilized a library of analytic source-site Green's functions computed in advance using the program FKRPROG (Saikia, 1994) for the crustal structure detailed in Table 2. Because seismic wave propagation through the onedimensional structure in Table 1 is radially symmetric, the Green's functions were computed from an array of point sources located at depths between 0.5 and $5 \mathrm{~km}$ and bedrock surface sites at distances between 1 and $20 \mathrm{~km}$ from the injection well. While full finite-fault ground motion calculations are required for events larger than a threshold magnitude (selected at $\mathrm{M}_{\mathrm{w}} 2.5$ in the present study), smaller events, for which fault rupture propagation effects are negligible, can be treated as point sources. This significantly reduces overall computation time, since a point 


\section{DRAFT}

Second Generation Toolset for Calculation of Induced Seismicity Risk Profiles

sources require only scaling of the Green's function by seismic moment whereas a finite source requires full convolution of the earthquake source-time function with the Green's function.

Table 1: Earthquake source simulation parameter values

\begin{tabular}{|l|l|l|}
\hline \multicolumn{1}{|c|}{ Parameter } & \multicolumn{1}{c|}{ Value } & \multicolumn{1}{c|}{ Data source } \\
\hline$\mu_{0}$ & $0.6-0.9$ & Generic aleatory distribution \\
\hline$\lambda$ & $18034.0 \mathrm{MPa}$ & Derived from well logs \\
\hline$\mu$ & $9290 \mathrm{MPa}$ & Derived from well logs \\
\hline$\sigma$ & $-0.7 \mathrm{MPa}$ & Derived from well data \\
\hline $\mathrm{d} \sigma / \mathrm{dz}$ & $0.02 \mathrm{MPa} \cdot \mathrm{m}^{-1}$ & Derived from well data \\
\hline$\tau$ & $4.0 \mathrm{MPa}$ & Derived from well data \\
\hline $\mathrm{V}$ & $1-2 \mathrm{~mm} \cdot \mathrm{y}^{-1}$ & Generic epistemic distribution \\
\hline $\mathrm{A} / \mathrm{b}$ & $0.3-0.5$ & Generic aleatory distribution \\
\hline $\mathrm{b}$ & 0.015 & Generic value \\
\hline $\mathrm{D}_{\mathrm{c}}$ & $15-35 \mu \mathrm{m}$ & Generic aleatory distribution \\
\hline $\mathrm{V}_{\mathrm{eq}}$ & $1 \mathrm{~m} \cdot \mathrm{s}^{-1}$ & Generic value \\
\hline $\mathrm{fA}$ & $0.1-0.3$ & Generic epistemic distribution \\
\hline $\mathrm{s}$ & $0.2-0.4$ & Generic epistemic distribution \\
\hline
\end{tabular}

\begin{tabular}{|c|c|c|c|c|}
\hline $\begin{array}{l}\text { Depth to top of } \\
\text { layer } \\
\text { km }\end{array}$ & $\underset{\mathrm{km}^{v_{p}} \mathrm{~s}^{-1}}{ }$ & $\begin{array}{c}\mathbf{v}_{\mathrm{s}} \\
\mathrm{km}_{\cdot \mathrm{s}^{-1}}\end{array}$ & $Q_{p}$ & $Q_{s}$ \\
\hline 0.00 & 2.50 & 1.50 & 50 & 50 \\
\hline 0.89 & 3.65 & 1.85 & 50 & 50 \\
\hline 1.75 & 4.20 & 2.20 & 50 & 50 \\
\hline 2.00 & 3.70 & 1.90 & 50 & 50 \\
\hline 2.80 & 4.50 & 2.50 & 50 & 50 \\
\hline 3.50 & 6.12 & 3.50 & 100 & 100 \\
\hline 3.60 & 6.12 & 3.50 & 100 & 100 \\
\hline 7.00 & 6.22 & 3.50 & 150 & 150 \\
\hline
\end{tabular}

Table 2:

Crustal

velocity

model

used to

generate

Green's

functions

Hazard and Risk Results: Figure 7 shows hazard curves calculated at Site 1 from earthquakes simulated on Fault 1 based on 20 epistemic realizations. Figures 7(a)-(c) show the mean hazard and $5^{\text {th }}, 50^{\text {th }}$ and $95^{\text {th }}$ percentile curves for three contiguous time periods. The first (0-200 years) covers the 200 years prior to injection, and so corresponds to the background seismicity on the fault. The second period (200-250 years) covers the first 50 years of injection, during which the pressure in the reservoir rises from hydrostatic to its peak. The third period (250-300 years) 


\section{DRAFT}

Second Generation Toolset for Calculation of Induced Seismicity Risk Profiles

corresponds to the relatively rapid fall-off from the peak pressure (see Figure 6). Figure 7(d) compares the mean hazard curves for the three time periods. The same suite of curves was also calculated for Sites 2 and 3.

The mean hazard curve for 200-250 years lies somewhat above the background (0-200 years) curve for acceleration levels between 3 and $20 \mathrm{~cm} / \mathrm{s} / \mathrm{s}$, and significantly above it at higher accelerations. However, the rapid fall-off in the 0-200 year curve does not look plausible. This may be an output error, but another possible explanation of this is that the burn-in time was insufficient, so that sufficient larger events had not yet been generated. The 200-250 year curve is significantly above the post-injection (250-300) years curve for all acceleration levels. The hazard behavior over the three periods is generally consistent with the seismicity seen in the example shown in Figure 6; i.e. the hazard during the injection interval is higher than both the background and the post-injection period of relatively suppressed seismicity.
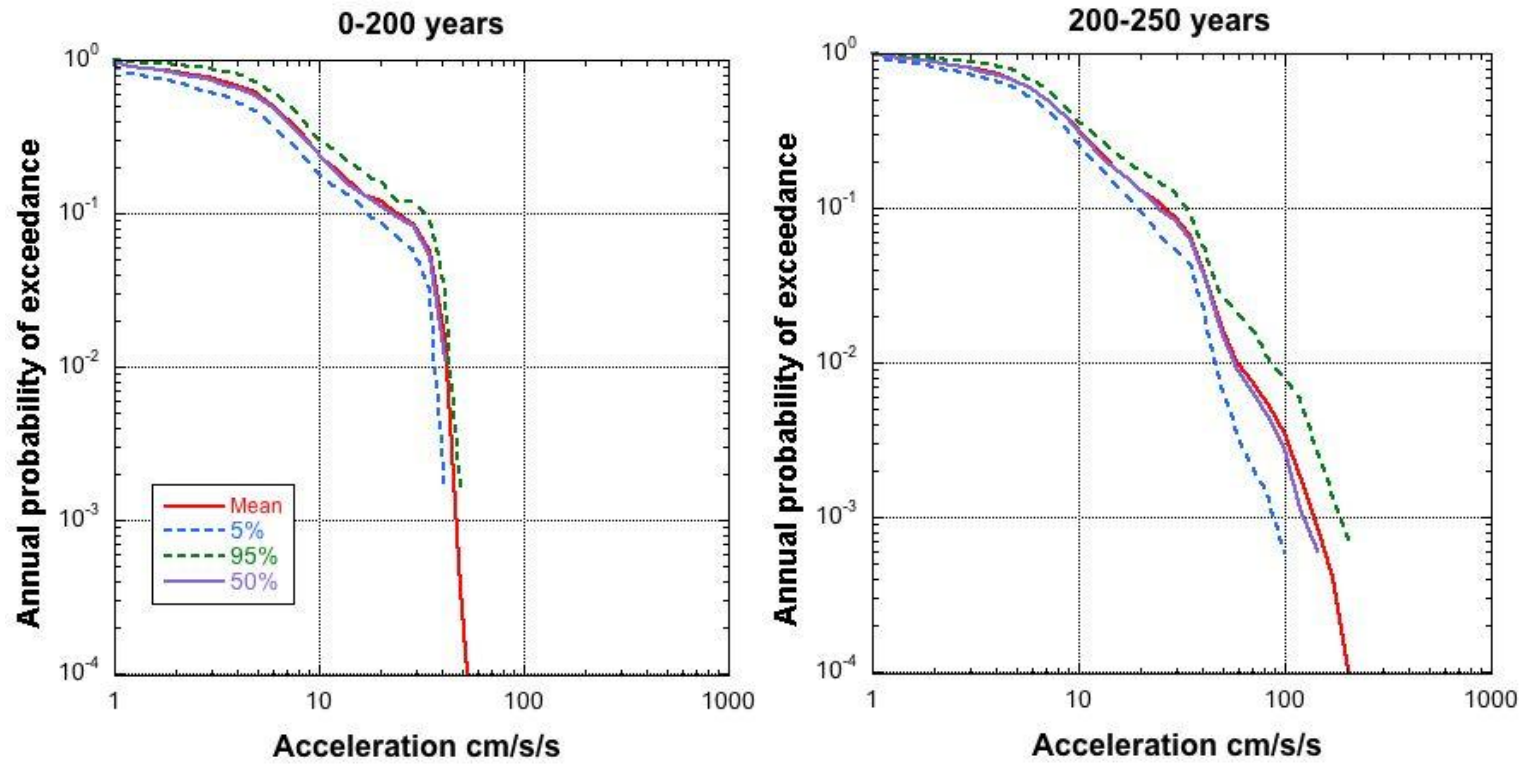


\section{DRAFT}

Second Generation Toolset for Calculation of Induced Seismicity Risk Profiles
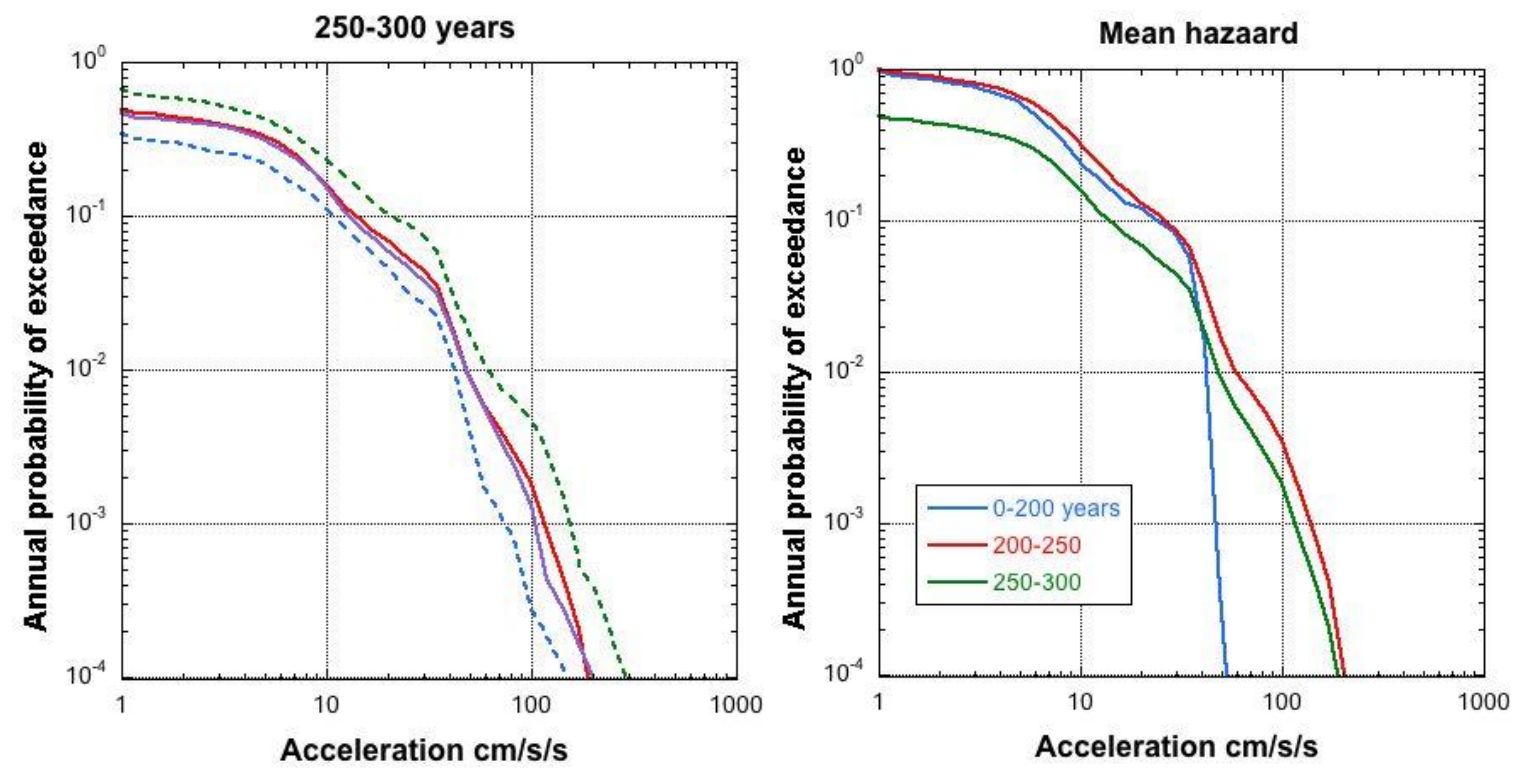

Figure 7: Single source seismic hazard curves calculated at Site 1 for time periods 0-200 (a), 200-250 (b) and 250-300 (c) years. Mean and $5^{\text {th }}, 50^{\text {th }}$ and $95^{\text {th }}$ percentile bounds are calculated from 25 epistemic realizations. The bottom right panel $(d)$ compares mean hazard curves for the three time periods.

The relatively small increase in hazard for the 3 to $20 \mathrm{~cm} / \mathrm{s} / \mathrm{s}$ acceleration range at first sight seem surprising given the substantial increase in the seismicity rate associated with injection. However, much of the increased activity over the 50-year injection period is at lower or higher magnitudes than the $\sim \mathrm{M}_{\mathrm{w}}$ 2.5-3.5 events that likely dominate the ground motions in this range. Because these events occur relatively frequently, they probably make the greatest contribution to the hazard at intermediate acceleration levels. If the example shown in Figure 6 is taken as generally representative, then the rate of occurrence of $\mathrm{M}_{\mathrm{w}} 2.5-3.5$ events during the first 50 years of injection is not much higher than in the first 200 years. There is a significant difference in the risk curves (Figure 8) between the two periods, however. This is because the nuisance risk is particularly sensitive to the increased occurrence during injection of small events that generate ground accelerations $\sim 10 \mathrm{~cm} . \mathrm{s}^{-1} . \mathrm{s}^{-1}$, the criterion selected to anchor the fragility curve.

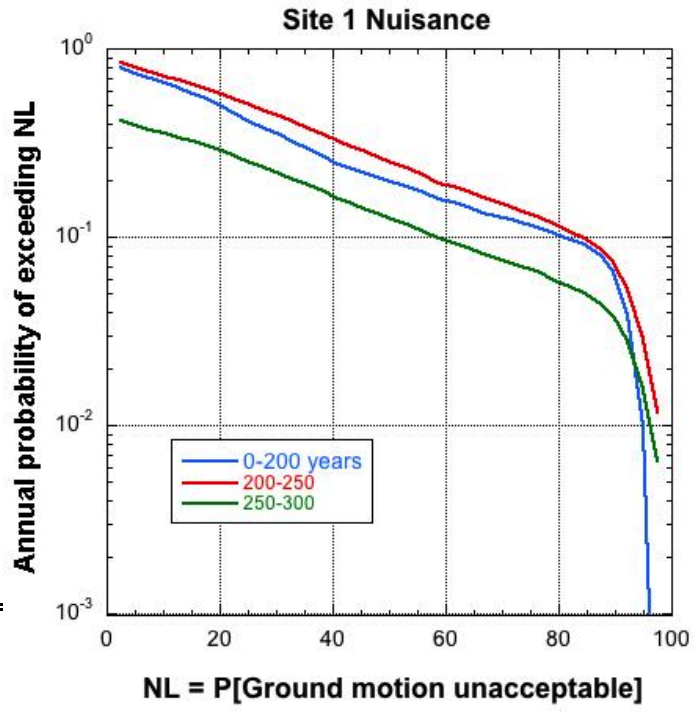




\section{DRAFT}

Second Generation Toolset for Calculation of Induced Seismicity Risk Profiles

Figure 8: Nuisance risk curves at Site 1 for the single-fault scenario for three time periods.

Figure 9 shows mean hazard curves at Sites 1, 2 and 3 from earthquakes generated by the twofault scenario using 20 epistemic realizations. The figure for each site compares the hazard for the 0-200 and 200-250 time periods. The comparison of the curves at Site 1 for the two time periods is consistent with the one-fault case (Figure 7d), except that in the two-fault case the 200-250-year curve is clearly above the background for all acceleration levels. The hazard during injection at higher ground accelerations is significantly higher for this scenario than in the single fault case - about a factor of 5 at $100 \mathrm{~cm} / \mathrm{s} / \mathrm{s}$ - for both time periods, reflecting the higher total seismicity rates generated by the two faults. The difference between the two scenarios is somewhat less at lower acceleration values. The differences between hazard during the injection period and the background hazard are much greater at all acceleration levels at sites Sites 2 and 3. As shown in Figure 9(d), the overall level of ground motion falls of with distance, as expected, and at Site 2 the difference between the two time periods in the $10-30 \mathrm{~cm} / \mathrm{s} / \mathrm{s}$ range is on the same order as that at accelerations higher than $100 \mathrm{~cm} / \mathrm{s} / \mathrm{s}$ at Site 1 . Figure 10 shows uncertainty bounds for the for 200-250-year two-fault hazard curves at the three sites. 


\section{DRAFT}

Second Generation Toolset for Calculation of Induced Seismicity Risk Profiles
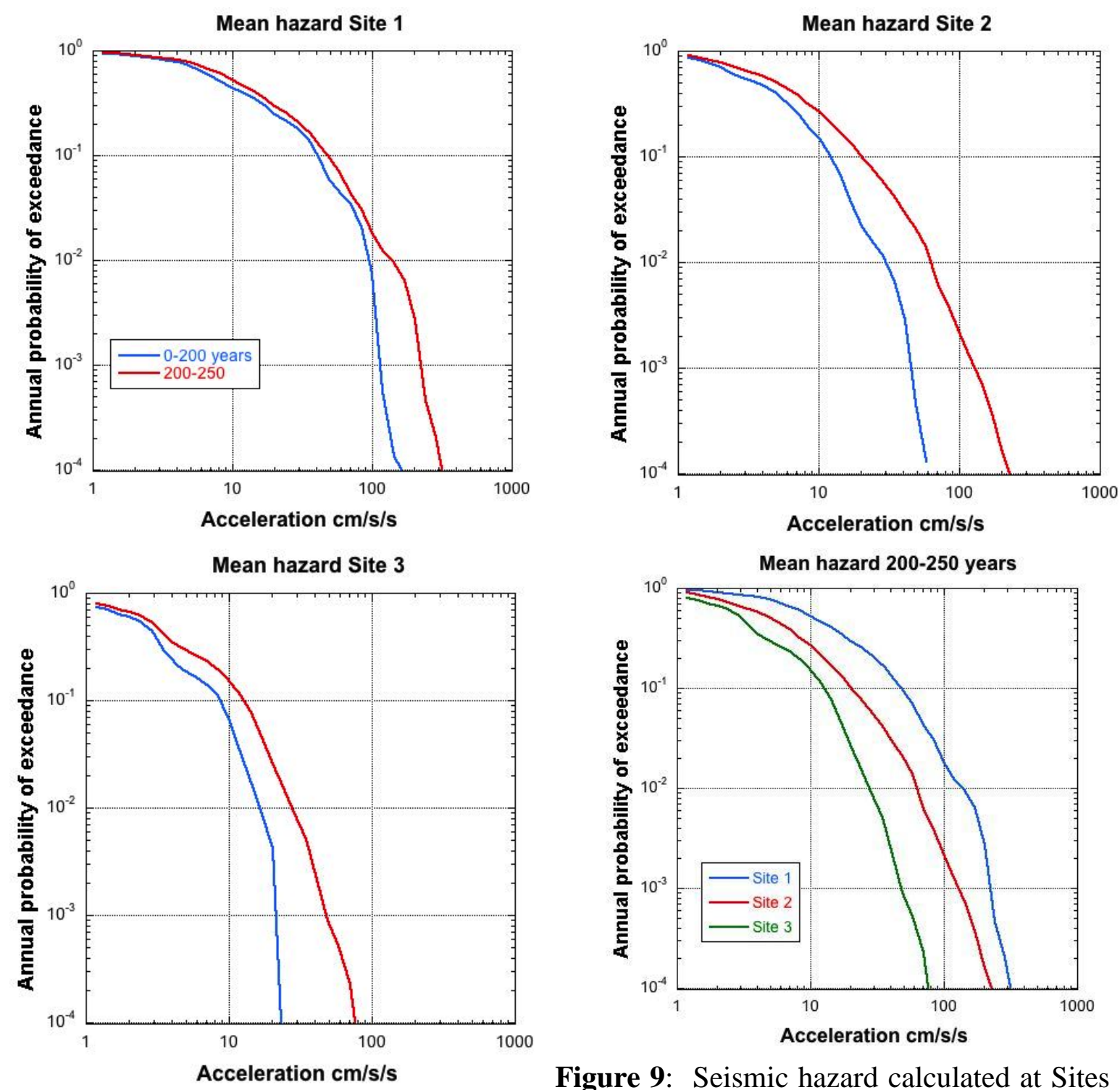

$2(b)$ and $3(c)$ for the two-fault scenario and for time periods 0-200 years and 200-250 years. The bottom right panel $(d)$ compares mean hazard curves calculated for the 200-250 year time period at the three sites. 


\section{DRAFT}

Second Generation Toolset for Calculation of Induced Seismicity Risk Profiles
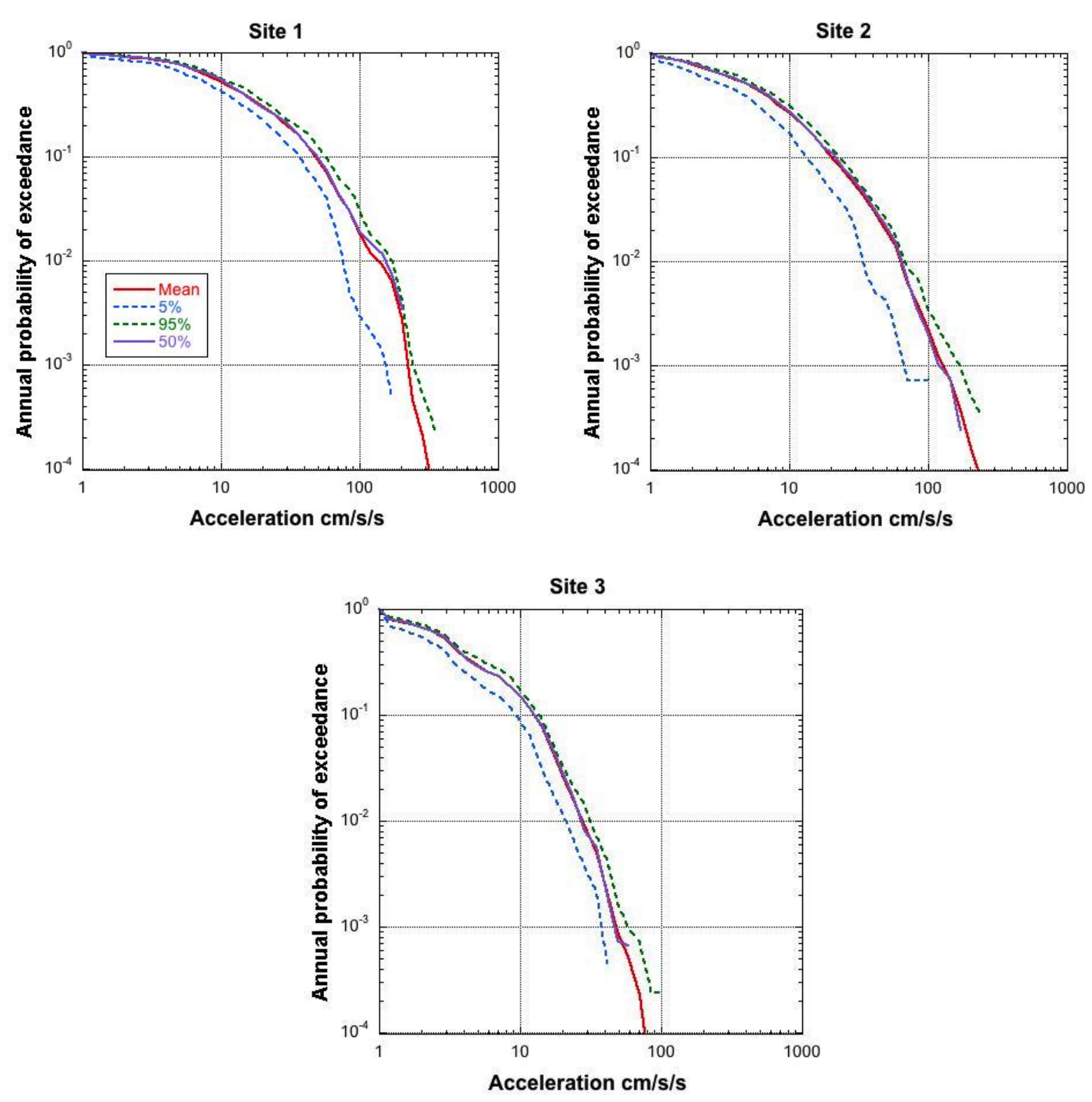

Figure 10: Two-fault scenario seismic hazard curves calculated at Sites $1(a), 2(b)$ and $3(c)$ for the time period 200-250 years showing mean and $5^{\text {th }}, 50^{\text {th }}$ and $95^{\text {th }}$ percentile bounds.

The risk of nuisance from ground motion at the three sites before and during injection is shown in Figure 11. The overall probability of nuisance at Site 1 is appreciably higher than in the single fault case (Figure 8), but the differences between the nuisance curves for the pre-injection and injection periods are similar for both cases. Consistent with the ground motion hazard, nuisance risk falls off rapidly with distance for all levels of unacceptability. Furthermore, there is a marked increase in the difference between the nuisance before and during injection, reflecting the predominant contribution of ground motion from relatively small events to the risk a short distances from the earthquake sources. 


\section{DRAFT}

Second Generation Toolset for Calculation of Induced Seismicity Risk Profiles 


\section{DRAFT}

Second Generation Toolset for Calculation of Induced Seismicity Risk Profiles

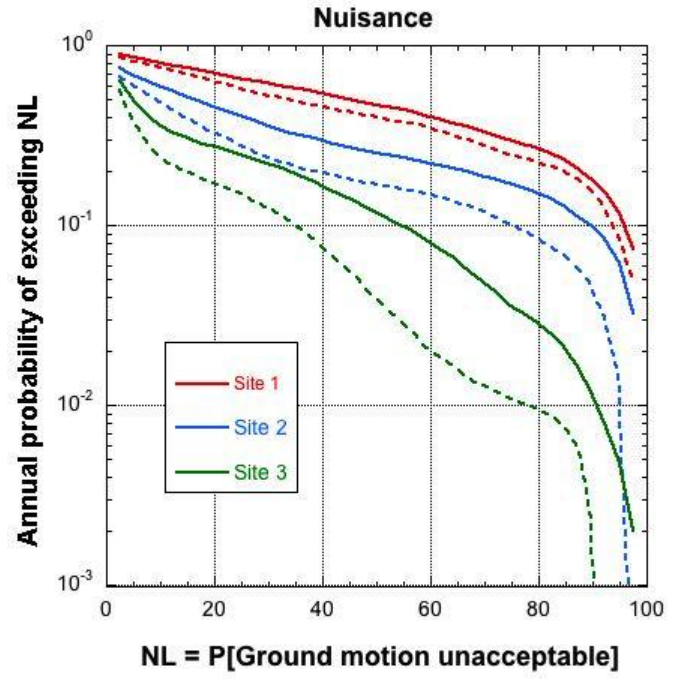

Figure 11: Nuisance risk at Sites 1, 2 and 3 calculated for the two-fault scenario. Nuisance risk for the pre-injection (0-200 years) and injection (200-250 years) periods are shown as the dashed and solid curves, respectively. 


\section{DRAFT}

Second Generation Toolset for Calculation of Induced Seismicity Risk Profiles

\section{DISCUSSION}

The results discussed above demonstrate the capabilities of the NRAP induced seismicity PSRA toolset at its present stage of development. The first basic objective of the Generation 2 development was to calculate the hazard from multiple faults over different time periods and at sites at different distances, based on multiple epistemic and aleatory realizations of seismicity and ground motion simulation parameters. The second objective was to develop nuisance fragility functions that can be combined with the hazard curves to carry the calculations forward to assess the risk of nuisance from induced seismicity. The second objective has achieved in full; to the best of our knowledge the fragility functions described in this report are the first to have been developed for the purpose of quantifying nuisance from seismic ground motion.

The first objective has also been met, but in a more modest sense. While the calculation of hazard and risk can be carried out using the toolset over multiple time periods at an arbitrary number of different sites, carrying out multiple realizations of seismicity catalogs for multiple faults still requires further work. The toolset can generate a relatively large number of catalogs from both one and two earthquake sources, but still has difficulty handling multiple realizations for more than two sources.

This problem is identified primarily as a programming issue, rather than a shortcoming of the fundamental design of the PSRA framework itself. In particular, there is an unresolved memory allocation issue across the three component programs that causes slow execution or errors within RSQSim at some stage of execution of multiple fault/multiple realization runs. This is due at least in part to the need to interface the C program RSQSim with the two other programs written in Fortran, and is particularly challenging because SYNHAZ is essentially a legacy program. Simulation times within RSQSim are also sometimes unacceptably long. This may happen when RSQSim is presented with certain combinations of rate-and-state parameters that are unphysical or difficult to reconcile. Although Trainor-Guitton et al. (2013) carried out an investigation of the sensitivity of simulated seismicity to individual parameters, there remains a need to investigate parameter combinations and possible correlations. Another possible source of slow processing times is the way in which pore pressures are interpolated on to fault planes defined by the epistemic realization.

The expectation is that these issues can be solved in a reasonable amount of time by continued programming work. However, there are two alternative approaches that can be considered at the present stage of development. The first is to decouple RSQSim from the Fortran codes. This can be achieved by building a library of seismicity catalogs by running in advance a large number of RSQSim simulations. These can be run automatically in batch mode - on a Linux cluster for example - to cover systematically the full range of epistemic and aleatory uncertainty distributions. The catalogs can then be randomly sampled by SIMRISK as input to the hazard and risk calculations. SIMRISK already has the capability to use catalog input. The second alternative that can be considered is to integrate the three codes within a Python wrapper. Which ever of the alternatives might be pursued, code parallelization will be required to achieve acceptable run times. The physics-based method employed by the NRAP toolset appears to be the most promising approach to assessing induced seismicity before $\mathrm{CO}_{2}$ injection begins. However, the viability of the method is subject to calibration and validation of RSQSim simulations against an induced seismicity data set recoded at an actual site. 


\section{DRAFT}

Second Generation Toolset for Calculation of Induced Seismicity Risk Profiles 


\section{DRAFT}

Second Generation Toolset for Calculation of Induced Seismicity Risk Profiles

\section{SUMMARY}

The simulation-based approach demonstrated in the report is being developed for induced seismicity hazard and risk analysis at the engineering design and regulatory phases of a project, before injection begins. During the planning stage, many simulation-based assessments can be run to explore ranges of different injection strategies and to assess their attendant risks. An additional advantage of this approach is that can be used to characterize the pre-injection background earthquake frequency-magnitude behavior in regions of low seismicity where the existing earthquake record is sparse. Because of the low hazard from naturally-occurring events, seismic monitoring networks in such areas are typically very sparse or non-existent so that the magnitude threshold for event detection is often as high as $\mathrm{M}_{\mathrm{w}} 3.5-4$.

Simulation-based seismic hazard and risk analysis can also be applied during and after injection. However, the induced seismicity data base built by seismic monitoring during the injection and post-shut-in phases characterizes the actual, evolving response of the geological system to injection and so will provide the primary input to forward projections of hazard and risk. The role of simulation in the analyses for these project phases is to determine physics-based models of time- and space-dependent earthquake occurrence on a site-specific basis to which the data can be fit in order to forecast risks and to determine future injection and reservoir management strategies. This is seen as a vital role for simulation because, unlike the assumption usually made in conventional PSHA, induced seismicity is non-stationary both in time and space.

The demonstration analyses described above suggest that seismicity falls of dramatically almost immediately after injection ceases and pressure begins to decline. This is generally consistent with observations at most injection operations, and suggests that reduction in flow rate and pressure and, ultimately, backflowing the well should form the basis for mitigation procedures. These can be initiated, for example, when earthquake occurrence frequency over a given magnitude range reaches a specified level. The greatest challenge is defining for a particular geological system what the appropriate thresholds are when there is no past record of the more extreme events. Physics-based flow and seismicity simulation utilizing the most complete characterization of the system parameters offers a promising approach to providing that capability. 


\section{DRAFT}

Second Generation Toolset for Calculation of Induced Seismicity Risk Profiles 


\section{DRAFT}

Second Generation Toolset for Calculation of Induced Seismicity Risk Profiles

\section{REFERENCES}

Ben-Zion, Y. Collective Behavior of Earthquakes and Faults: Continuum-discrete Transitions, Progressive Evolutionary Changes, and Different Dynamic Regimes. Rev. Geophys. 2008, 46, RG4006, 70 p.

Dieterich, J. Earthquake Simulations with Time-dependent Nucleation and Long-range Interactions. Nonlinear Processes in Geophysics 1995, 2, 109-120.

Dowding, C.H., Construction Vibrations, Prentice Hall 1996.

Foxall, W., Hutchings, L., Johnson, S., and Savy, J. First Generagtion Toolset for Calculation of Induced Seismicity Hazard Profiles. NRAP-TRS-III-006-2012; NRAP Technical Report Series; U.S. Department of Energy, National Energy Technology Laboratory: Morgantown, WV, 2012; 10p.

HAZUS 2013: The Federal Emergency Management Agency's (FEMA's) Methodology for Estimating Potential Losses from Disasters. www.fema.gov/hazus/\#3.

Majer, E., Nelson, J., Robertson-Tait, A., Savy, J., and Wong, I. Best Practices for Addressing Induced Seismicity Associated With Enhanced Geothermal Systems (EGS) 2012.

Marone, C. Laboratory-derived Friction Laws and their Application to Seismic Faulting. Ann. Rev. Earth. Planet. Sci. 1998, 26, 643-696.

Richards-Dinger, K., Dieterich, J. RSQSim Earthquake Simulator. Seismol. Res. Let. 2012, 83, 983-990.

Saikia, C. Modified Frequency-wavenumber Algorithm for Regional Seismograms using Filon's Quadrature: Modeling of Lg Waves in Eastern North America. Geophys. J. Int. 1994, $118,142-158$.

Trainor-Guitton, W, Foxall, W., and Johnson, S. Parameter Sensitivity Analysis for the Earthquake Simulation Program RSQSim. Draft NRAP Technical Report, in review 2012 


\section{DRAFT}

Second Generation Toolset for Calculation of Induced Seismicity Risk Profiles

This page intentionally left blank 


\section{nrap \\ National Risk}

Assessment Partnership

\section{Technical Leadership Team}

Jens Birkholzer

LBNL Technical Coordinator

Lawrence Berkeley National Laboratory

Berkeley, CA

\section{Grant Bromhal}

NETL Technical Coordinator

Lead, Reservoir Working Group

Office of Research and Development

National Energy Technology Laboratory

Morgantown, WV

\section{Chris Brown}

PNNL Technical Coordinator

Lead, Groundwater Working Group

Pacific Northwest National Laboratory

Richmond, WA

Susan Carroll

LLNL Technical Coordinator

Lawrence Livermore National Laboratory

Livermore, CA

\section{Laura Chiaramonte}

Lead, Natural Seals Working Group

Lawrence Livermore National Laboratory

Livermore, CA

\section{Tom Daley}

Lead, Monitoring Working Group

Lawrence Berkeley National Laboratory

Berkeley, CA

George Guthrie

Technical Director, NRAP

Office of Research and Development

National Energy Technology Laboratory

Pittsburgh, PA

\section{Rajesh Pawar}

LANL Technical Coordinator

Lead, Systems Modeling Working Group

Los Alamos National Laboratory

Los Alamos, NM

Tom Richard

Deputy Technical Director, NRAP

The Pennsylvania State University

NETL-Regional University Alliance

State College, PA

Brian Strazisar

Lead, Wellbore Integrity Working Group Office of Research and Development National Energy Technology Laboratory

Pittsburgh, PA 


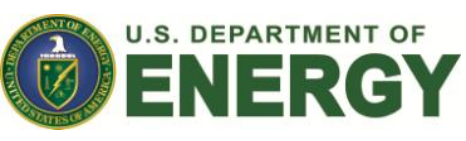

Sean Plasynski

Deputy Director

Strategic Center for Coal

National Energy Technology Laboratory

U.S. Department of Energy

\section{Jared Ciferno}

Director

Office of Coal and Power R\&D

National Energy Technology Laboratory

U.S. Department of Energy

Robert Romanosky

Technology Manager

Office of Coal and Power R\&D

National Energy Technology Laboratory

U.S. Department of Energy

\section{Regis Conrad}

Director

Division of Cross-cutting Research

Office of Fossil Energy

U.S. Department of Energy

\section{nrap}

National Risk

Assessment Partnership

NRAP Executive Committee

Cynthia Powell

Director

Office of Research and Development

National Energy Technology Laboratory

U.S. Department of Energy

Alain Bonneville

Laboratory Fellow

Pacific Northwest National Laboratory

Donald DePaolo

Associate Laboratory Director

Energy and Environmental Sciences

Lawrence Berkeley National Laboratory

Melissa Fox

Chair, NRAP Executive Committee

Program Manager

Applied Energy Programs

Los Alamos National Laboratory

\section{Julio Friedman}

Chief Energy Technologist

Lawrence Livermore National

Laboratory

George Guthrie

Technical Director, NRAP

Office of Research and Development

National Energy Technology Laboratory
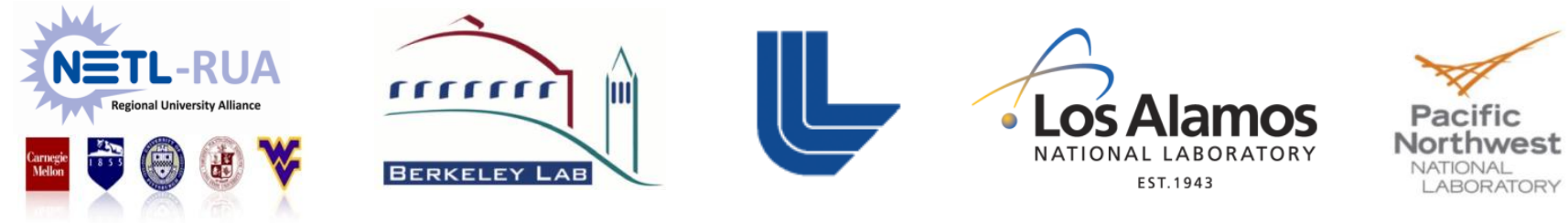